\title{
Plasma KL-6 Predicts the Development and Outcome of Bronchopulmonary Dysplasia
}

\author{
TOHRU OGIHARA, KAZUYA HIRANO, TAKAO MORINOBU, HAN-SUK KIM, SATORU OGAWA, MAYO HIROI, SHINYA OUE, \\ RYOICHI BAN, SEIGO HIRA, MASASHI HASEGAWA, SHIGEO YAMAOKA, AND MASAKO YASUI
}

\begin{abstract}
Department of Neonatal Medicine [T.O., K.H., T.M., Sa.O., May.H., Sh.O., R.B., S.H., Mas.H. S.Y., M.Y.], Perinatal Center, Osaka Medical College, Osaka 569-8686, Japan; Department of Pediatrics [H.-S.K.], Division of Neonatology, Seoul National University College of Medicine, Seoul National University Hospital, Chongno-gu, Seoul 110-744, Korea
\end{abstract}

\begin{abstract}
Circulating KL-6 is a specific indicator of pulmonary injury affecting the alveolar epithelium and interstitium. Our preliminary study suggested the usefulness of plasma KL- 6 as a marker of bronchopulmonary dysplasia (BPD). To confirm the diagnostic value of KL-6 for BPD as well as to determine the reference range, we conducted a larger prospective study in 135 preterm infants $<32 \mathrm{wk}$ GA. Among the infants without oxygen dependence at a postconceptional age of $36 \mathrm{wk}$, the plasma KL-6 level showed no significant association with GA at any time. Among 42 infants $<28$ wk GA, plasma KL-6 levels were significantly higher in those with moderate/ severe BPD compared with those with no/mild BPD. A plasma level of $199 \mathrm{U} / \mathrm{mL}$ at $1 \mathrm{wk}$ or $232 \mathrm{U} / \mathrm{mL}$ at $2 \mathrm{wk}$ was an excellent predictor of moderate/severe BPD $<28$ wk GA (positive predictive value of $83 \%$ and $80 \%$, respectively). Unlike nonspecific markers of inflammation or fibrosis, KL-6 objectively reflects the severity of pulmonary injury irrespective of the treatment or the radiographic changes. Therefore, not only as a good marker, measurement of KL-6 may also help to provide new insights into the pathogenesis of BPD. (Pediatr Res 60: 613-618, 2006)
\end{abstract}

$\mathrm{T}^{3}$ The term BPD, or neonatal chronic lung disease, represents a syndrome of respiratory distress caused by chronic lung parenchymal injury. Most definitions of BPD are solely based on the requirement for oxygen therapy (1-3), but oxygen dependence per se does not necessarily mean the presence of lung injury. Additional radiographic criteria do not necessarily indicate the extent of lung damage either, and are too subjective for consistent interpretation to be achieved $(4,5)$. Accordingly, there is still no well-accepted definition of BPD. To overcome these limitations, it would be desirable to develop a specific and objective marker that accurately reflects the severity of lung parenchymal injury (6).

KL-6 is a circulating high molecular weight mucinous glycoprotein and is the extracellular soluble region of MUC-1 mucin possessing an undefined sialylated carbohydrate chain that is recognized by KL-6 antibody (7). Kohno et al. (8) originally reported KL-6 as a murine MAb directed against a human pulmonary adenocarcinoma cell line, but the term

Received January 10, 2006; accepted June 22, 2006.

Correspondence: Tohru Ogihara, M.D., Department of Neonatal Medicine, Perinatal Center, Osaka Medical College, 2-7, Daigaku-machi, Takatsuki, Osaka 569-8686, Japan; e-mail: ped025@poh.osaka-med.ac.jp

This work was supported by a Grant-in-Aid for Scientific Research (16591082) from the Japan Society for the Promotion of Science.
"KL-6" has subsequently come to be used for the KL-6 antigen itself. In healthy humans, KL-6 is preferentially expressed by alveolar type II cells and bronchiolar epithelial cells (7). Circulating levels of KL-6 are markedly increased in patients with various interstitial lung diseases $(9-11)$, despite remaining within the normal range in patients with many other noninterstitial lung diseases such as bacterial pneumonia, asthma, and pulmonary emphysema (12). The characteristic pathologic features of interstitial pneumonia are type II pneumocyte hyperplasia with a variable amount of fibrosis (13), and both of these are also found in BPD. It is thought that injury to the alveolar epithelium and basement membrane is necessary for pulmonary fibrosis to occur (13). During reepithelialization after alveolar injury, type II cells proliferate to cover the damaged area and then differentiate into type I cells. Regenerating type II cells strongly express KL-6 antigen and may be the main source of increased plasma KL-6 levels. Even without significant injury or proliferation, alveolar type II cells are also known to secrete KL-6 protein when stimulated by pro-inflammatory cytokines (10). Because KL-6 is a very large glycoprotein $\left(M_{r}>200 \mathrm{kD}\right)$, increased permeability of the pulmonary epithelium and leakage through the capillary endothelium alone would not raise its blood level. To produce a high circulating KL-6 level, severe damage to both the pulmonary epithelium and interstitium would be necessary (7). In addition, serum KL-6 levels are known to be well correlated with KL-6 levels in bronchoalveolar lavage fluid $(10,14)$ and can be used to predict the response to corticosteroid therapy in patients with interstitial lung disease (15). Accordingly, circulating KL-6 is recognized as a specific indicator of pulmonary injury affecting the alveolar epithelium and interstitium (7).

A previous immunohistochemical study revealed that type II cells obtained from premature lungs expressed KL-6 as early as 23 wk GA (16). We previously found an increase of the plasma KL-6 level in infants with BPD, suggesting that

Abbreviations: BPD, bronchopulmonary dysplasia; BW, birth weight; CAM, chorioamnionitis; $\mathbf{F i o}_{\mathbf{2}}$, fraction of inspired oxygen; MIP, macrophage inflammatory protein; PCA, postconceptional age; PROM, premature rupture of the membranes; TNF- $\alpha$, tumor necrosis factor- $\alpha$

DOI: 10.1203/01.pdr.0000242361.47408.51 
KL-6 was an early marker of BPD and an indicator of its severity (17). The present prospective study was performed on a larger scale to determine the reference range of plasma KL-6 in relation to postnatal age and to confirm the diagnostic value of KL-6 for BPD.

A possible influence of antenatal inflammation on the development of BPD was previously reported $(18,19)$, with elevated cord blood IgM levels being detected in BPD infants with intrauterine infection (20). Several subsequent studies have investigated various inflammatory cytokines in both cord blood and bronchoalveolar lavage fluid just after birth in infants who subsequently developed BPD (21), and some of these studies have demonstrated that cord blood levels of IL-6 and other cytokines may be useful for predicting the development of BPD $(22,23)$. Therefore, to compare KL-6 with other markers, we also measured IgM and various cytokines [including IL-1 $\beta$, IL-6, TNF- $\alpha$, IL-8, and macrophage inflammatory protein (MIP)- $1 \alpha$ ] in the cord blood.

\section{METHODS}

The study protocol was approved by the ethics committee of our hospital and investigations were only performed after informed consent had been obtained from the parents of the subjects.

Subjects. Among the infants admitted to the NICU of Osaka Medical College Hospital between January 2001 and June 2005, all eligible preterm infants with a GA $<32$ wk were prospectively enrolled in this study. Exclusion criteria at entry were 1) congenital heart disease, 2) multiple malformations, and 3) a documented chromosomal abnormality. Infants who died of nonrespiratory causes or were transferred before reaching a postconceptional age (PCA) of $36 \mathrm{wk}$, or from whom both cord blood and a 1-wk blood sample were not obtained, were also excluded from the final analysis. GA was established in order of priority based on the last menstrual period or Ballard assessment (24). BPD was defined according to the National Institute of Child Health and Human Development/National Heart, Lung, and Blood Institute Workshop definition (National Institutes of Health consensus definition) for infants with a GA $<32 \mathrm{wk}(3)$, i.e. treatment with oxygen $>21 \%$ for at least $28 \mathrm{~d}$. Then the infants were classified into the following three subgroups at 36 wk PCA: mild BPD (fraction of inspired oxygen $\left(\mathrm{FiO}_{2}\right)=$ $21 \%)$, moderate BPD $\left(21 \%<\mathrm{FiO}_{2}<30 \%\right)$, and severe $\mathrm{BPD}\left(\mathrm{FiO}_{2} \geq 30 \%\right.$ and/or positive pressure assistance). To assess objective changes on chest $\mathrm{x}$-ray films, a single radiologist (who was unaware of the clinical course and KL-6 levels) counted the number of small $(1-10 \mathrm{~mm}$ in diameter), welldefined, round cystic lucencies with thin walls ("bubbles") (25). Typical radiographic bubbles are shown in Figure 1. Chorioamnionitis (CAM) was defined by maternal signs such as fever $\left(\geq 38^{\circ} \mathrm{C}\right)$ or tachycardia $(\geq 100 / \mathrm{min})$ in the presence of both leukocytosis $\left(\geq 10000 / \mathrm{mm}^{3}\right)$ and an increased C-reactive protein level $(\geq 1.5 \mathrm{mg} / \mathrm{dL})$. Histologic CAM was diagnosed if polymorphonuclear leukocytes were seen in the fetal membranes and was graded according to Blanc (26). We obtained heparinized blood samples from the umbilical cord vein or directly from the infants by venipuncture once every 1-2 wk during hospitalization (salvaging the residual blood after routine examinations had been performed). The blood was immediately centrifuged at $3000 \times g$ for $10 \mathrm{~min}$ at $4^{\circ} \mathrm{C}$ to obtain plasma, which was stored at $-80^{\circ} \mathrm{C}$.

Measurements. Plasma KL-6 was measured using a sandwich-type ELISA kit (Eitest KL-6, Eisai Co. Ltd., Tokyo, Japan) according to the method reported previously (17), which requires $10 \mu \mathrm{L}$ of plasma. The levels of IL-1 $\beta$, IL-6, IL-8, TNF- $\alpha$, and MIP-1 $\alpha$ were also measured using ELISA kits (BioSource International, Camarillo, CA). IgM was measured by a turbidimetric immunoassay.

Evaluation of total oxygen supplementation. As described previously, the total cumulative oxygen supplementation for each infant was calculated by using the following equation: $\Sigma$ total oxygen supplementation $=$ additional administered oxygen concentration $\left(\mathrm{Fio}_{2}-21\right)[\%] \times$ duration [hours] (27).

Statistical analysis. Differences between two groups were assessed by MannWhitney $U$ test for continuous variables or by Fisher exact test for categorical data. Plasma KL-6 levels were compared between groups at several time points by Kruskal-Wallis test, and intergroup differences were determined by Mann-
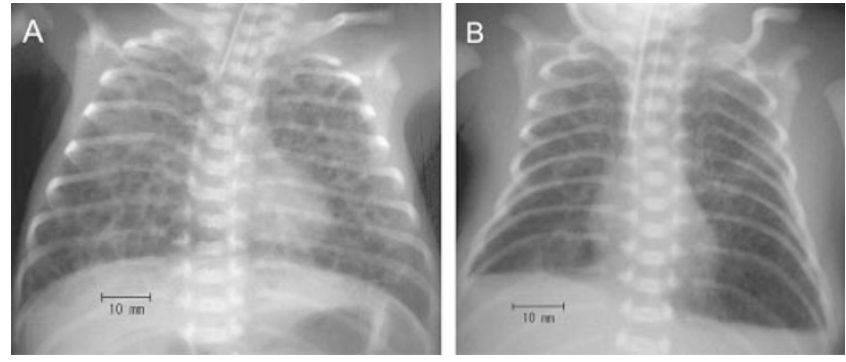

Figure 1. (A) Chest x-ray film of a 32-d-old male infant (born at 25.6 wk GA and a body weight of $800 \mathrm{~g}$ ). Histologic examination of the placenta showed severe CAM (Blanc grade 3). The plasma KL-6 level reached a maximum of $1554 \mathrm{U} / \mathrm{mL}$ on d 28, although the cord blood level was only $138 \mathrm{U} / \mathrm{mL}$. He required supplemental oxygen until $167 \mathrm{~d}$ after birth. $(B)$ Chest x-ray film obtained at $21 \mathrm{~h}$ after birth in a male infant delivered at $30 \mathrm{~d}$ after premature rupture of the membranes (PROM) (24.7 wk GA and a body weight of $806 \mathrm{~g}$ ). Histologic examination of the placenta showed severe CAM (Blanc grade 3). The plasma KL-6 level reached a maximum of $2300 \mathrm{U} / \mathrm{mL}$ on d 28 compared with a cord blood level of $132 \mathrm{U} / \mathrm{mL}$. He developed persistent pulmonary hypertension just after birth and required nitric oxide inhalation until $\mathrm{d} 8$ of life. His respiratory function progressively deteriorated and he died of respiratory failure on d 89 .

Whitney $U$ test. In all analyses, $p<0.05$ was considered to be significant. Data were analyzed using SPSS ver. 11.0 (SPSS Inc., Chicago, IL) or StatView ver. 5.0 (SAS Institute Inc., Cary, NC) statistical software, as was appropriate.

\section{RESULTS}

During the study period, 155 infants with a GA $<32$ wk passed our initial inclusion criteria. Among these infants, 11 died (10 had a GA $<28 \mathrm{wk}$ ) and 4 were transferred before reaching 36 wk PCA. In five other infants, both cord blood and 1-wk blood samples were not obtained. Finally, a total of 135 infants ( $87 \%$ of all eligible infants) were enrolled in the study.

Reference plasma Kl-6 levels for the infants $<32$ wk GA. First, we determined the normal reference values of plasma KL-6 at various postnatal ages up to $8 \mathrm{wk}$ after birth using the data obtained from the entire 135 infants and taking note of any variation with GA or $\mathrm{BW}$. When the subjects were restricted to 42 infants $<28$ wk GA, only 4 had no BPD and 19 had mild BPD. In contrast, among 93 infants $\geq 28$ wk GA, 71 infants had no BPD and only 13 had mild BPD. Accordingly, about half of the infants $<28$ wk GA required supplementary oxygen for at least $28 \mathrm{~d}$, possibly due to pulmonary immaturity, and thus might be classified as having mild BPD even if there was no apparent lung damage. Among the infants with a GA $\geq 28$ wk GA and considerable lung injury, oxygen dependence may persist beyond $36 \mathrm{wk}$ PCA in most cases and they would be classified as having moderate or severe BPD. In other words, if infants have marked parenchymal lung damage, they should be classified as moderate/severe BPD irrespective of their gestational age. Therefore, we combined infants with no BPD and mild BPD into a single reference group, which included a total of 107 infants with the following distribution: $(\mathrm{GA}<28 \mathrm{wk})=23,(28 \leq \mathrm{GA}<30 \mathrm{wk})=36$, and $(30 \leq \mathrm{GA}<32 \mathrm{wk})=48$. Their data are shown in Table 1 . As presented in Figure 2, plasma KL-6 was not significantly associated with either GA or BW in this group, and the KL-6 
Table 1. Reference ranges for plasma $K L-6(U / m L)$ in infants at $<32$ wk gestation based on the data obtained from infants with no/mild BPD according to the criteria of the National Institutes of Health consensus definition (2000)

\begin{tabular}{lrr}
\hline & Mean \pm SD & Median (range) \\
\hline Cord blood & $91 \pm 43$ & $78(31-301)$ \\
d 7 & $176 \pm 99$ & $155(72-735)$ \\
d 14 & $178 \pm 80$ & $153(58-431)$ \\
d 28 & $169 \pm 78$ & $151(74-627)$ \\
d 42 & $141 \pm 55$ & $127(61-359)$ \\
d 56 & $127 \pm 44$ & $110(79-261)$ \\
36 wk PCA & $133 \pm 46$ & $122(74-261)$ \\
\hline
\end{tabular}

Data were obtained from a total of 107 infants: $(\mathrm{GA}<28 \mathrm{wk})=23,(28 \leq$ $\mathrm{GA}<30 \mathrm{wk})=36$, and $(30 \leq \mathrm{GA}<32 \mathrm{wk})=48$.
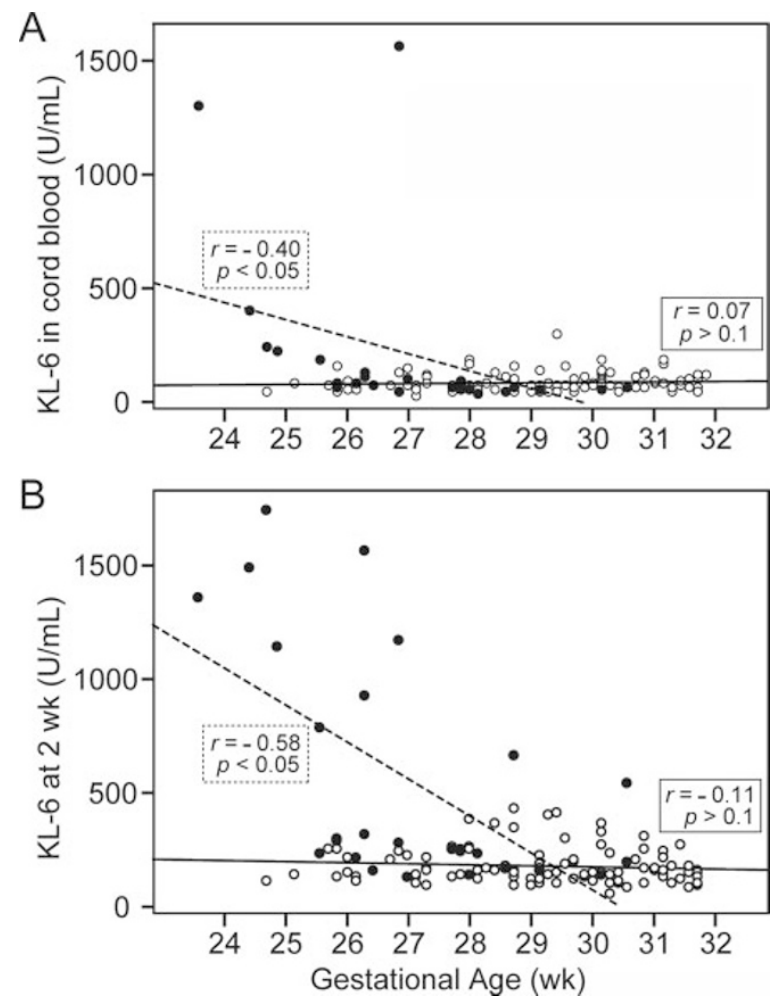

Figure 2. The relationship between GA and plasma KL-6 levels estimated by Pearson's correlation coefficient analysis. The correlation of GA and plasma KL-6 levels in $(A)$ cord blood, and $(B)$ at $2 \mathrm{wk}$ (representative of postnatal data). Open circles and the solid line represent infants with no/mild BPD, whereas closed circles and the dotted line show infants with moderate/severe BPD according to the criteria of the National Institutes of Health consensus definition (2000).

level was comparable between no BPD infants and mild BPD infants at all times. In contrast, when the subjects were restricted to infants with moderate/severe BPD, plasma KL-6 showed a significant inverse correlation with both GA and BW at all times.

The plasma KL- 6 level doubled by 1 wk after birth and then gradually declined beyond $4 \mathrm{wk}$ of life. Age dependence of plasma KL-6 was statistically significant during the 8 -wk period after birth in both the infants with no/mild BPD and those with moderate/severe BPD. For the entire 135 infants, there was still a significant relationship between plasma KL-6 and postnatal age $(p<0.001$, repeated-measures ANOVA).
Comparison of plasma Kl-6 between moderate/severe $B P D$ and no/mild BPD group $<28$ wk $\boldsymbol{G A}$. We then compared plasma KL-6 levels and several other variables between BPD infants and the reference group. When the 93 infants $\geq 28$ wk GA were selected, the moderate/severe BPD group contained only 9 subjects who had a significantly lower GA and BW than those of the no/mild BPD group. Among the 42 infants $<28$ wk GA, however, there were no differences of GA and BW between the two groups. Because the occurrence of BPD is known to be strongly associated with low GA and low BW, it would be better to validate KL-6 in a population with comparable GA and BW values. In addition, clinically intractable BPD is almost exclusively found in extremely premature infants these days. Therefore, we analyzed the two groups obtained after restricting the GA to less than 28 wk. Table 2 summarizes the clinical characteristics of these groups. Because placental pathology was only obtained in $60 \%$ of the subjects, the combined incidence of clinical and/or pathologic CAM is presented. If there was inconsistency between the clinical and pathologic diagnoses of CAM, the pathologic findings were accepted. The incidence of PROM, CAM, and RDS was comparable between the two groups, but the moderate/severe BPD group had a significantly higher grade of $\mathrm{CAM}$. $\mathrm{FiO}_{2}$ on each day of life only differed at $36 \mathrm{wk}$ PCA, whereas the total oxygen supplementation required over various intervals showed significant differences both within

Table 2. Clinical characteristics of infants at $<28$ wk gestation who had moderate/severe BPD or no/mild BPD according to the criteria of the National Institutes of Health consensus definition (2000)

\begin{tabular}{|c|c|c|}
\hline & $\begin{array}{c}\text { Moderate/severe BPD } \\
(n=19)\end{array}$ & $\begin{array}{l}\text { No/mild BPD } \\
\quad(n=23)\end{array}$ \\
\hline Male, $n(\%)$ & $14(74)$ & $9(39)$ \\
\hline Gestational age (wk) & $26.3(23.6-27.9)$ & $27.0(24.7-27.9)$ \\
\hline Body weight (g) & $908(512-1,266)$ & $932(544-1,220)$ \\
\hline PROM, $n(\%)$ & $13(68)$ & $16(70)$ \\
\hline PROM (h) & $24(0-1,200)$ & $12(0-886)$ \\
\hline CAM, $n(\%)$ & $13(68)$ & $15(65)$ \\
\hline CAM (Blanc score) & $3(0-3)^{*}$ & $1(0-3)$ \\
\hline Cesarean section, $n(\%)$ & $11(58)$ & $19(83)$ \\
\hline Apgar score at $1 \mathrm{~min}$ & $3(1-7)$ & $4(1-9)$ \\
\hline Apgar score at $5 \mathrm{~min}$ & $6(2-8)$ & $7(2-9)$ \\
\hline RDS at birth, $n(\%)$ & $11(58)$ & $11(48)$ \\
\hline Duration of PDA (d) & $3(0-19)$ & $5(0-23)$ \\
\hline Blood transfusion (mL/kg) & $40(0-120)^{*}$ & $0(0-80)$ \\
\hline Postnatal steroid use, $n(\%)$ & $15(79) \dagger$ & $7(30)$ \\
\hline Duration of ventilation (d) & $15(0-139)$ & $5(0-50)$ \\
\hline Duration of $\mathrm{O}_{2}$ therapy (d) & $88(59-240) \ddagger$ & $48(18-76)$ \\
\hline $\mathrm{FiO}_{2}$ at $\mathrm{d} 7(\%)$ & $27(21-50)$ & $23(21-90)$ \\
\hline $\mathrm{FiO}_{2}$ at $\mathrm{d} 14(\%)$ & $30(21-60)$ & $28(21-85)$ \\
\hline $\mathrm{FiO}_{2}$ at $\mathrm{d} 28(\%)$ & $33(21-60)$ & $32(21-45)$ \\
\hline $\mathrm{FiO}_{2}$ at $36-w \mathrm{kCA}(\%)$ & $30(22-100) \div$ & $21(21-21)$ \\
\hline Total $\mathrm{O}_{2}$ within wk 1 & $2,407(775-9,432)^{*}$ & $1,410(69-11,678)$ \\
\hline Total $\mathrm{O}_{2}$ during $1-2$ wk & $1,500(0-4,272)$ & $1,395(0-9,602)$ \\
\hline Total $\mathrm{O}_{2}$ during $2-4 \mathrm{wk}$ & $5,964(464-21,564)^{*}$ & $3,922(182-8,971)$ \\
\hline Total $\mathrm{O}_{2}$ during $4-8 \mathrm{wk}$ & $8,650(2,112-44,439) \neq$ & $3,312(0-12,296)$ \\
\hline
\end{tabular}

Values are expressed as the median (range). Differences between the two groups were assessed by Mann-Whitney $U$ test for continuous variables or by Fisher exact test for categorical data.

$* p<0.05, \dagger p<0.01$, and $\ddagger p<0.001 v s$ no/mild BPD group.

PDA, patent ductus arteriosus. 
the first week of life and beyond the second week. The duration of patent ductus arteriosus was comparable, whereas the total volume of blood transfused and the use of postnatal steroid therapy were significantly greater in the moderate/ severe BPD group.

Plasma KL-6 was significantly elevated in the infants with moderate/severe BPD throughout the study period, while the KL-6 level of the no/mild BPD infants was relatively stable and remained within the reference ranges (Fig. 3). As shown in Table 3, however, cord blood levels of IgM and all five cytokines tested were comparable between the two groups.

Prediction of moderate/severe BPD with Kl-6 in $<28$ wk $\boldsymbol{G A}$ infants. Using cut-off values selected with receiver operating characteristic curves, we compared the diagnostic performance of KL-6 for predicting the development of moderate/severe BPD $<28$ wk GA (Table 4). The KL-6 levels at both 1 and 2 wk of life showed excellent predictive power. With respect to the area under the curve (AUC), the order of ranking was 2 wk of life, 1 wk of life, and cord blood (Fig. 4). In addition, the predictive value of the cord blood KL-6 level was generally superior to that of cord blood IgM and cytokine levels (data not shown).

Clinical features of infants with extremely high KL-6 levels. By setting a cut-off value at 3 SD above the mean KL-6 level for the entire 135 subjects on each day of life, we found seven infants who had extremely high maximum plasma KL-6 levels ( $>1000 \mathrm{U} / \mathrm{mL}$ at least once during their clinical course). To make a comparison with age-matched controls, we selected infants with the nearest GA from among the remaining 128 subjects. If two or more infants had the same GA, we chose the one with the nearest BW. As can be seen in Table 5, the high KL-6 group had distinctive clinical features. They were all extremely premature, all had severe BPD, and all had a prolonged requirement for high concentrations of oxygen.

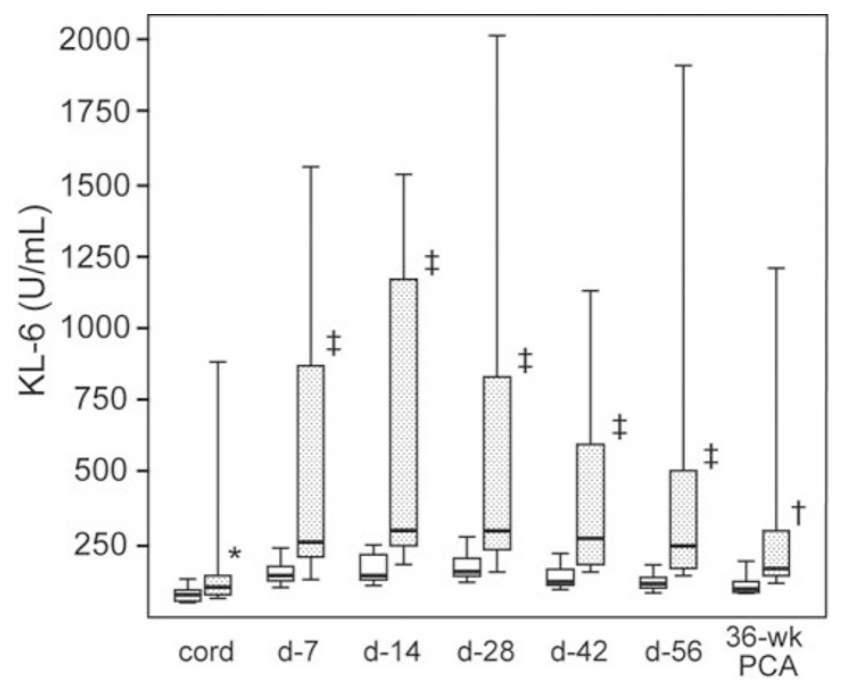

Figure 3. Box and whisker plot showing the median with interquartile range (box) and the 10th and 90th percentiles (whiskers) of plasma KL-6 during an 8 -wk period after birth and at a PCA of $36 \mathrm{wk}$ for infants with no/mild BPD (white bars) or moderate/severe BPD (dotted bars) according to the criteria of the National Institutes of Health consensus definition (2000). ${ }^{*} p<0.05$, $\dagger p<0.01$, and $\ddagger p<0.001$ vs no/mild BPD by Kruskal-Wallis test followed by Mann-Whitney $U$ test.
Table 3. Cord blood IgM and cytokine levels in infants at $<28 w k$ gestation who had moderate/severe BPD or no/mild BPD according to the criteria of the National Institutes of Health consensus definition (2000)

\begin{tabular}{lcc}
\hline & $\begin{array}{c}\text { Moderate/Severe BPD } \\
(n=19)\end{array}$ & $\begin{array}{c}\text { No/Mild BPD } \\
(n=23)\end{array}$ \\
\hline IgM $(\mathrm{mg} / \mathrm{dL})$ & $7.7(2.7-154)$ & $5.3(2.3-36.6)$ \\
IL-1 $\beta(\mathrm{pg} / \mathrm{mL})$ & $1.6(0.3-102.2)$ & $0.7(0.1-13.8)$ \\
IL-6 $(\mathrm{pg} / \mathrm{mL})$ & $11.4(0.1-553.2)$ & $16.5(0.8-507.6)$ \\
IL-8 $(\mathrm{pg} / \mathrm{mL})$ & $17.2(0.9-2270.7)$ & $18.6(3.6-680.7)$ \\
TNF- $\alpha(\mathrm{pg} / \mathrm{mL})$ & $5.8(2.1-157)$ & $8.7(0.6-64.3)$ \\
MIP-1 $\alpha(\mathrm{pg} / \mathrm{mL})$ & $21.9(5.8-220.4)$ & $28.4(5.4-63.1)$ \\
\hline
\end{tabular}

Values are expressed as the median (range).

Table 4. Performance of KL-6 in predicting moderate/severe BPD at $<28$ wk gestation

\begin{tabular}{lccc} 
& Cord blood & 1 wk & 2 wk \\
\hline Cut-off value (u/mL) & 83 & 199 & 232 \\
Specificity (\%) & 65 & 87 & 82 \\
Sensitivity (\%) & 74 & 79 & 84 \\
PPV (\%) & 64 & 83 & 80 \\
NPV (\%) & 75 & 83 & 86 \\
\hline
\end{tabular}

The cut-off values were obtained by using receiver operating characteristic curves. PPV, positive predictive value; NPV, negative predictive value.

$\mathrm{FiO}_{2}$ on d 28 was comparable between the groups, but $\mathrm{Fio}_{2}$ at $36 \mathrm{wk}$ PCA and total oxygen supplementation from birth were significantly higher in the high KL-6 group. Although these infants were more likely to have severe CAM and plasma KL-6 levels were significantly correlated with the grade of CAM, their cord blood levels of IgM and cytokines were comparable to those of the control infants (data not shown). Radiographic bubbles were abundant and developed very early (by d 3 at the latest) (Fig. 1). These seven infants had very severe respiratory impairment and often fatal, with three infants (43\%) dying of respiratory failure (on d 68, 89, and 139).

\section{DISCUSSION}

When our subjects were restricted to infants $<32$ wk GA who did not show oxygen dependence at 36 wk PCA, the plasma KL-6 level was not influenced by GA (Table 1 and Fig. 2). In addition, KL-6 levels were comparable to those measured in full term infants without any respiratory problems, including the cord blood level and that measured at $1 \mathrm{wk}$ of life (data not shown). This means that, even at a GA of $<28$ wk, infants with no/mild BPD showed successful adaptation to the postnatal environment without much lung parenchymal damage despite significant oxygen supplementation. In contrast, the plasma KL-6 levels of the infants with moderate/ severe BPD was inversely correlated with GA at all times (Fig. 2). This suggests that, once the infants had suffered significant lung injury, lung parenchymal damage becomes more severe as GA decreases.

There was a significant difference of cord blood KL-6 levels between infants at a GA $<28$ wk who had moderate/severe BPD or no/mild BPD. Some of the infants with moderate/ severe BPD had very high cord blood KL-6 levels that exceeded $1000 \mathrm{U} / \mathrm{mL}$ (Fig. 3). Although there is little clinical 

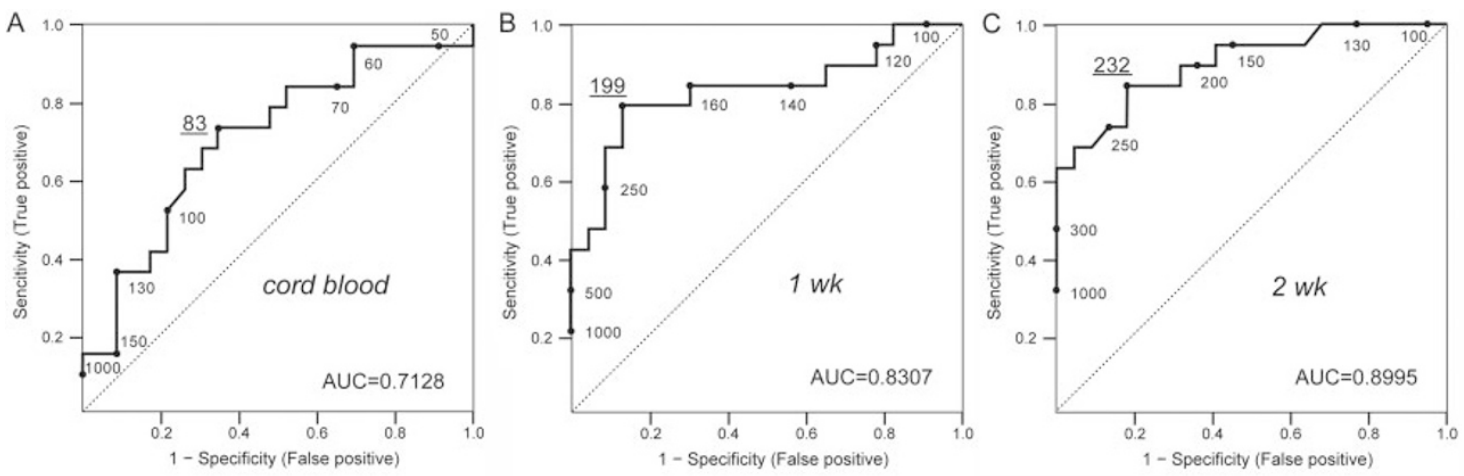

Figure 4. Receiver operating characteristic curves for plasma KL-6 levels in $(A)$ cord blood, $(B)$ at 1 wk, and $(C)$ at 2 wk of life. The diagonal dotted line indicates a hypothetical test with no predictive value. Numbers on the solid line are KL-6 concentrations (U/mL), with cut-off values underlined. AUC, area under the curve.

Table 5. Comparison between infants with extremely high plasma KL-6 levels (exceeding the mean +3 SD at least once during hospitalization) and age-matched controls

\begin{tabular}{|c|c|c|}
\hline & $\begin{array}{l}\text { High KL-6 } \\
\quad(n=7)\end{array}$ & $\begin{array}{l}\text { Control } \\
(n=7)\end{array}$ \\
\hline \multicolumn{3}{|l|}{ BPD } \\
\hline Mild BPD ( $n)$ & $0^{*}$ & 5 \\
\hline Moderate BPD (n) & 0 & 1 \\
\hline Severe BPD $(n)$ & $7 \ddagger$ & 0 \\
\hline Gestational age (wk) & $25.6(23.6-26.9)$ & $25.9(24.7-26.9)$ \\
\hline Body weight (g) & $800(512-1,072)$ & $932(544-1,256)$ \\
\hline CAM $(n)$ & 7 & 5 \\
\hline CAM (Blanc score) & $3(2-3) \dagger$ & $0(0-1)$ \\
\hline $\begin{array}{l}\text { Duration of } \\
\quad \text { ventilation (d) }\end{array}$ & $71(7-139) \dagger$ & $5(0-30)$ \\
\hline $\begin{array}{c}\text { Duration of } \mathrm{O}_{2} \\
\text { therapy }(\mathrm{d})\end{array}$ & $128(68-240) \dagger$ & $61(45-91)$ \\
\hline $\mathrm{FiO}_{2}$ at $\mathrm{d} 28(\%)$ & $50(30-60)$ & $33(24-40)$ \\
\hline $\begin{array}{r}\mathrm{FiO}_{2} \text { at } 36-w \mathrm{k} \\
\mathrm{PCA}(\%)\end{array}$ & $60(40-100) \dagger$ & $21(21-25)$ \\
\hline Total $\mathrm{O}_{2}$ within wk 1 & $3,897(1,732-9,432)^{*}$ & $1,950(687-3,362)$ \\
\hline Total $\mathrm{O}_{2}$ during $0-4 \mathrm{wk}$ & $20,273(13,572-27,911) \dagger$ & $9,109(2,415-10,801)$ \\
\hline Total $\mathrm{O}_{2}$ during $4-8 \mathrm{wk}$ & $25,178(13,116-44,439) \dagger$ & $4,969(1,667-9,996)$ \\
\hline Total $\mathrm{O}_{2}$ during $8-12 \mathrm{wk}$ & $16,771(13,366-53,088) \dagger$ & $296(0-2,345)$ \\
\hline \multicolumn{3}{|c|}{ Bubbles on chest $\mathrm{x}$-ray } \\
\hline d $28(n)$ & $7 \ddagger$ & 0 \\
\hline d 28 (n/film) & $39(17-68) \ddagger$ & $0(0-0)$ \\
\hline 36 wk PCA $(n)$ & $7 *$ & 2 \\
\hline 36 wk PCA (n/film) & $27(10-44) \dagger$ & $0(0-16)$ \\
\hline \multicolumn{3}{|l|}{ KL-6 (U/mL) } \\
\hline cord blood & $138(116-1,570)^{*}$ & $82(50-161)$ \\
\hline d 7 & $1,250(410-2,410) \dagger$ & $146(107-257)$ \\
\hline d 14 & $1,360(786-1,740) \dagger$ & $207(113-252)$ \\
\hline d 28 & $1,554(506-4,480) \dagger$ & $168(120-285)$ \\
\hline 36-wk PCA & $878(189-2,860) \dagger$ & $116(87-179)$ \\
\hline Death $(n)$ & 3 & 0 \\
\hline
\end{tabular}

Values are expressed as the median (range). Differences between the two groups were assessed by Mann-Whitney $U$ test for continuous variables or by Fisher exact test for categorical data.

$* p<0.05, \dagger p<0.01$, and $\ddagger p<0.001$ vs age-matched controls.

evidence about whether or not lung injury practically occurs in fetuses with CAM (28), this possibly means that some of the infants with BPD had already suffered parenchymal lung injury while in utero. Previous studies using oxygen dependence on d 28 to define BPD showed a significant association between cord blood cytokine levels and the development of
BPD $(22,23)$. Whereas cytokine levels were comparable between moderate/severe BPD and no/mild BPD in our series, we also found that cord blood IL-6 and IL-8 levels were significantly higher in BPD infants than those in no BPD infants.

However, in most of our moderate/severe BPD infants, the plasma KL-6 level increased rapidly after birth to reach about three times the cord blood value within the first few weeks of life and remained continuously elevated to at least $8 \mathrm{wk}$ of age (Fig. 3). This pattern of plasma kinetics was especially prominent in the BPD infants with extremely high KL-6 levels (Table 5). These findings clearly show that the infants suffered from continuing postnatal pulmonary epithelial and interstitial injury, and suggest a possible role of various postnatal factors in the development of BPD, such as oxygen toxicity $(27,29$, 30), barometric/volumetric trauma, and infection. Therefore, in most cases with moderate/severe BPD, it seems likely that prenatal lung injury associated with CAM usually has a priming effect that predisposes fetal lungs to become more susceptible to subsequent toxic agents, rather than lung injury being directly induced by intrauterine infection.

The distinctive radiographic feature in our seven infants with extremely high KL-6 levels was the early development of numerous bubbles in the lungs (Table 5 and Fig. 1). The radiographic findings resembled those seen in Wilson-Mikity syndrome (31). However, according to the original description, the clinical course of Wilson-Mikity syndrome is generally very mild, with a low $\mathrm{Fio}_{2}$, no need for respiratory support, delayed onset of respiratory symptoms and radiographic abnormalities, and death usually being due to nonrespiratory problems in fatal cases $(25,32)$. Similar clinical features have been reported in type I BPD (33), atypical BPD (34), and so-called new BPD (35). According to Hodgeman, these four types of BPD may all be variants of the same condition (36). However, our high KL-6 cases were different, especially with respect to the early onset of respiratory failure and radiographic abnormalities, as well as the poor outcome with a high mortality rate. These "fulminant" cases may be more similar to Japanese infants who have been reported as "neonatal pulmonary emphysema" (37), while a milder case has been reported in a relatively mature infant (38). A recent report from the UK also described similar emphysematous 
changes from as early as $5 \mathrm{~d}$ after birth in extremely premature infants and suggested a close association with colonization by Ureaplasma urealyticum (39). However, the condition of these infants seemed to be much milder since the median duration of ventilation was only $33 \mathrm{~d}$ (versus $76 \mathrm{~d}$ in our seven infants). Because we did not culture ureaplasma, we could not assess the role of this organism.

Unlike nonspecific markers of inflammation or fibrosis, KL-6 is a specific and sensitive indicator of parenchymal lung damage, so it objectively reflects the severity of pulmonary injury irrespective of oxygen demand, the mode of respiratory support, or the radiographic changes. A very recent report suggested the usefulness of serum KL-6 level for monitoring pulmonary function in BPD infants (40). Therefore, KL-6 is not only a useful predictor of BPD, but may contribute to establishing a more objective definition of this condition (not solely based on the intensity of respiratory support) and may also provide new insights into its pathogenesis.

Acknowledgments. The authors thank Drs. Akiko Akedo, Kayoko Iwai, Michi Ojima, Yuka Wada, Noriko Oue, Miho Fukui, Teruhisa Hoshika, Hiromi Ogihara, and Makoto Mino for their kind assistance and advice, as well as Eisai Co., Ltd., and Ikuo Yamamoto for technical support. We also thank Kazuo Matsumoto from Access Laboratory for statistical analysis and the NICU nursing staff for their help with sample collection.

\section{REFERENCES}

1. Avery ME, Tooley WH, Keller JB, Hurd SS, Bryan MH, Cotton RB, Epstein MF, Fitzhardinge PM, Hansen CB, Hansen TN 1987 Is chronic lung disease in low birth weight infants preventable? A survey of eight centers. Pediatrics 79:26-30

2. Shennan AT, Dunn MS, Ohlsson A, Lennox K, Hoskins EM 1988 Abnormal pulmonary outcomes in premature infants: prediction from oxygen requirement in the neonatal period. Pediatrics $82: 527-532$

3. Jobe AH, Bancalari E 2001 Bronchopulmonary dysplasia. Am J Respir Crit Care Med 163:1723-1729

4. Bancalari E, Abdenour GE, Feller R, Gannon J 1979 Bronchopulmonary dysplasia: clinical presentation. J Pediatr 95:819-823

5. Ogawa Y, Fujimura M, Goto A, Kawano T, Kondo T, Nakae N, Nishida A, Ohno T, Takeuchi Y, Togari H, Maeta H, Oguchi K 1992 Epidemiology of neonatal chronic lung disease in Japan. Acta Paediatr Jpn 34:663-667

6. Bancalari E, Claure N, Sosenko IR 2003 Bronchopulmonary dysplasia: changes in pathogenesis, epidemiology and definition. Semin Neonatol 8:63-71

7. Kohno N 1999 Serum marker KL-6/MUC1 for the diagnosis and management of interstitial pneumonitis. J Med Invest 46:151-158

8. Kohno N, Akiyama M, Kyoizumi S, Hakoda M, Kobuke K, Yamakido M 1988 Detection of soluble tumor-associated antigens in sera and effusions using novel monoclonal antibodies, KL-3 and KL-6, against lung adenocarcinoma. Jpn J Clin Oncol 18:203-216

9. Kohno N, Yokoyama A, Hirasawa Y, Kondo K, Fujino S, Abe M, Hiwada K 1997 Comparative studies of circulating KL-6, type III procollagen N-terminal peptide and type IV collagen 7S in patients with interstitial pneumonitis and alveolar pneumonia. Respir Med 91:558-561

10. Ishizaka A, Matsuda T, Albertine KH, Koh H, Tasaka S, Hasegawa N, Kohno N, Kotani T, Morisaki H, Takeda J, Nakamura M, Fang X, Martin TR, Matthay MA, Hashimoto S 2004 Elevation of KL-6, a lung epithelial cell marker, in plasma and epithelial lining fluid in acute respiratory distress syndrome. Am J Physiol Lung Cell Mol Physiol 286:L1088-L1094
11. Al-Salmi QA, Walter JN, Colasurdo GN, Sockrider MM, Smith EO, Takahashi H, Fan LL 2005 Serum KL-6 and surfactant proteins A and D in pediatric interstitial lung disease. Chest 127:403-407

12. Ohnishi H, Yokoyama A, Kondo K, Hamada H, Abe M, Nishimura K, Hiwada K, Kohno N 2002 Comparative study of KL-6, surfactant protein-A, surfactant protein-D, and monocyte chemoattractant protein-1 as serum markers for interstitial lung diseases. Am J Respir Crit Care Med 165:378-381

13. Crouch E 1990 Pathobiology of pulmonary fibrosis. Am J Physiol 259:L159-L184

14. Kohno N, Awaya Y, Oyama T, Yamakido M, Akiyama M, Inoue Y, Yokoyama A, Hamada H, Fujioka S, Hiwada K 1993 KL-6, a mucin-like glycoprotein, in bronchoalveolar lavage fluid from patients with interstitial lung disease. Am Rev Respir Dis 148:637-642

15. Yokoyama A, Kohno N, Hamada H, Sakatani M, Ueda E, Kondo K, Hirasawa Y, Hiwada K 1998 Circulating KL-6 predicts the outcome of rapidly progressive idiopathic pulmonary fibrosis. Am J Respir Crit Care Med 158:1680-1684

16. Sun AP, Ohtsuki Y, Fujita J, Ishida T, Yoshinouchi T, Kohno N 2003 KL-6, a human MUC1 mucin, is expressed early in premature lung. Respir Med 97:964-969

17. Ogihara T, Hirano K, Morinobu T, Ogawa S, Hiroi M, Ban R, Ogihara H, Tamai H $2000 \mathrm{KL}-6$, a mucinous glycoprotein, as an indicator of chronic lung disease of the newborn. J Pediatr 137:280-282

18. Watterberg KL, Demers LM, Scott SM, Murphy S 1996 Chorioamnionitis and early lung inflammation in infants in whom bronchopulmonary dysplasia develops. Pediatrics 97:210-215

19. Jobe AH, Ikegami M 2001 Antenatal infection/inflammation and postnatal lung maturation and injury. Respir Res 2:27-32

20. Fujimura M, Takeuchi T, Ando M, Funato M, Shimada S, Tsujimoto A, Kanaya S, Kozuki K, Morimoto SK 1983 Elevated immunoglobulin M levels in low birthweight neonates with chronic respiratory insufficiency. Early Hum Dev 9:27-32

21. Speer CP 2003 Inflammation and bronchopulmonary dysplasia. Semin Neonatol $8: 29-38$

22. Yoon BH, Romero R, Kim KS, Park JS, Ki SH, Kim BI, Jun JK 1999 A systemic fetal inflammatory response and the development of bronchopulmonary dysplasia. Am J Obstet Gynecol 181:773-779

23. An H, Nishimaki S, Ohyama M, Haruki A, Naruto T, Kobayashi N, Sugai T, Kobayashi Y, Mori M, Seki K, Yokota S 2004 Interleukin-6, interleukin-8, and soluble tumor necrosis factor receptor-I in the cord blood as predictors of chronic lung disease in premature infants. Am J Obstet Gynecol 191:1649-1654

24. Ballard JL, Khoury JC, Wedig K, Wang L, Eilers-Walsman BL, Lipp R 1991 New Ballard Score, expanded to include extremely premature infants. J Pediatr 119:417423

25. Hodgman JE, Mikity VG, Tatter D, Cleland RS 1969 Chronic respiratory distress in the premature infant. Wilson-Mikity syndrome. Pediatrics 44:179-195

26. Blanc WA 1959 Amniotic infection syndrome: pathogenesis, morphology and significance in circumnatal mortality. Clin Obstet Gynecol 2:705-734

27. Ogihara T, Okamoto R, Kim HS, Nagai A, Morinobu T, Moji H, Kamegai H, Hirano K, Ogihara H, Tamai H, Mino M 1996 New evidence for the involvement of oxygen radicals in triggering neonatal chronic lung disease. Pediatr Res 39:117-119

28. Schmidt B, Cao L, Mackensen-Haen S, Kendziorra H, Klingel K, Speer CP 2001 Chorioamnionitis and inflammation of the fetal lung. Am J Obstet Gynecol 185:173177

29. Ogihara T, Hirano K, Morinobu T, Kim HS, Hiroi M, Ogihara H, Tamai H 1999 Raised concentrations of aldehyde lipid peroxidation products in premature infants with chronic lung disease. Arch Dis Child Fetal Neonatal Ed 80:F21-F25

30. Saugstad OD 2001 Chronic lung disease: oxygen dogma revisited. Acta Paediatr 90:113-115

31. Wilson MG, Mikity VG 1960 A new form of respiratory disease in premature infants. Am J Dis Child 99:489-499

32. Swyer PR, Delivoria-Papadopoulos M, Levison H, Reilly BJ, Balis JU 1965 The pulmonary syndrome of Wilson and Mikity. Pediatrics 36:374-384

33. Wung JT, Koons AH, Driscoll JM Jr, James LS 1979 Changing incidence of bronchopulmonary dysplasia. J Pediatr 95:845-847

34. Charafeddine L, D’Angio CT, Phelps DL 1999 Atypical chronic lung disease patterns in neonates. Pediatrics 103:759-765

35. Jobe AJ 1999 The new BPD: an arrest of lung development. Pediatr Res 46:641-643

36. Hodgman JE 2003 Relationship between Wilson-Mikity syndrome and the new bronchopulmonary dysplasia. Pediatrics 112:1414-1415

37. Fujimura M, Kitajima H, Nakayama M 1993 Increased leukocyte elastase of the tracheal aspirate at birth and neonatal pulmonary emphysema. Pediatrics 92:564-569

38. Takami T, Kumada A, Takei Y, Miyajima T, Hoshika A 2003 A case of WilsonMikity syndrome with high serum KL-6 levels. J Perinatol 23:56-58

39. Theilen U, Lyon AJ, Fitzgerald T, Hendry GM, Keeling JW 2004 Infection with Ureaplasma urealyticum: is there a specific clinical and radiological course in the preterm infant? Arch Dis Child Fetal Neonatal Ed 89:F163-F167

40. Yamane M, Yokoyama N 2004 Serum KL-6 level and pulmonary function in preterm infants with chronic lung disease. Kobe J Med Sci 50:131-140 